\title{
Efficacy of Modified Vavoua and Nzi Traps in the Capture of Stable Flies: A Preliminary Field Trial in Cameroon
}

\author{
Sevidzem Silas Lendzele ${ }^{1^{*}}$, Zinga Koumba Christophe Roland ${ }^{2}$, Mamoudou Abdoulmoumini ${ }^{3}$, \\ Koumba Aubin Armel ${ }^{2}$, Mintsa Nguema Rodrigue ${ }^{2}$, Acapovi-Yao Genevieve Lydie ${ }^{4}$, M'batchi \\ Bertrand $^{5}$, Jacques François Mavoungou ${ }^{2,5}$ \\ ${ }^{1}$ Ecole Doctorale des Grandes Ecoles (EDGE), Laboratoire d'Ecologie Vectorielle (LEV-IRET), BP: 13354, \\ Libreville, Gabon \\ ${ }^{2}$ Institut de Recherche en Ecologie Tropicale (IRET), BP 13354, Libreville, Gabon \\ ${ }^{3}$ Department of Parasitology and Parasitological Diseases, School of Veterinary Medicine and Sciences, \\ University of Ngaoundere, P.O. Box 455, Ngaoundere, Cameroon \\ ${ }^{4}$ Université Félix Houphouët-Boigny, UFR Biosciences 22, BP: 582; Abidjan 22, Côte d'Ivoire \\ ${ }^{5}$ Université des Sciences et Techniques de MASUKU, BP 941, Franceville, Gabon
}

*Corresponding Authors: Sevidzem Silas Lendzele, Ecole Doctorale des Grandes Ecoles (EDGE), Laboratoire d'Ecologie Vectorielle (LEV-IRET), BP: 13354, Libreville, Gabon.

\begin{abstract}
There is need for a simple, cheap and efficient collection and control tool for the different stable fly-species in hyper-infested foci. The efficacy of a modified unbaited Vavoua trap (MVT) was compared with an unbaited Nzi as a standard. Each trap type was set either inside or outside the cattle overnight pen with rotation taking place after four days for eight days in September 2018 in Ngaoundere. Fly collection was made every 24 hours and sorted using standard identification keys. In total, 2105 hematophagous flies were caught and constituted of 1417 S. niger niger (89 S.n/t/d), 124 S. calcitrans (8 S.c/t/d), 562 Musca spp. (25 $\mathrm{m} / \mathrm{t} / \mathrm{d})$ and 2 Chrysops distinctipennis $(0.1 \mathrm{Cd} / \mathrm{t} / \mathrm{d})$. The overall mean catches with the MVT $(50.96 \pm 57.16)$ was higher than with the Nzi $(27.43 \pm 27.73)$, with no statistically significant difference $(t=0.9, d f=46.0$, $P=0.37)$. Higher mean catches were recorded outside the overnight cattle pen (47.79 \pm 55.27$)$ than inside $(39.83 \pm 55.40)$ with no statistically significant difference $(t=0.5, d f=46.0, P=0.62)$. Stable flies and tabanids were highly caught outside the overnight stable, while Musca spp. were highly caught inside. In conclusion, the MVT had similar efficacy and specificity as Nzi and can serve as a simple and efficient tool for the survey and control of stable flies in the Adamawa plateau and elsewhere.
\end{abstract}

Keywords: Modified vavoua, Nzi, Efficacy, stable flies, tabanids, Ngaoundere.

\section{INTRODUCTION}

The control of most haematophagous insect vectors especially Stomoxyinae can be effectively conducted using collective approaches such as sanitation, biological, mechanical and chemical (Bastien, 2008). Talking of biological control, Baleba et al., (2020) reported on the potential pathogen, predators and parasites that can control stable flies. The chemical approach includes the use of insecticides. Due to the high biting insect infestation rates of livestock farms in Ngaoundere, farmers have devised certain control measures like bush fires and use of insecticides (veterinary and agricultural)to manage flies (Sevidzem et al., 2019a; Sevidzem et al., 2019c). The use of insecticide incorporated screens is a major tool used by the Special Mission for Tsetse Erradication (MSEG) to control tsetse and other biting flies in Ngaoundere and other infested areas and its efficacy to control tsetse and other dipterous insect vectors in the Adamawa and North regions of Cameroon has already been reported (Mamoudou et al., 2017; Sevidzem et al., 2019c). Some insecticides have been reported to be resistant to stable flies (Tainchum et al., 2018; Olafson et al., 2019), therefore it is important to consider an alternative approach. The physical or mechanical control approach is based on the use of traps like box trap supplemented with alsynite fibre glass sticky panels (Williams, 1973) and was reported to be efficient for the control of stable flies. The blue-black cloth traps particularly the Vavoua trap has been reported to be highly specific tostable flies (Sevidzem and Mavoungou, 2019; Hiol et al., 2019; Sevidzem et al., 2019d). According to Solórzano et al., (2015), the Nzi is more 
efficient than Vavoua in the collection of stable flies, but the Nzi is large and need several tension points that makes it very difficult to transport and set up in the field. Also, the Vavoua trap is very efficient, expensive and not commercially available in local markets. Therefore, there is need for an efficient, simplified and available trap to farmers for the control of stable flies and subsequently reduce the diseases they transmit.

This study focuses on the design of a simple blue black trap known as the modified vavoua trap (MVT) as well as to compare its efficacy and specificity with the Nzi trap as the standard.

\section{Materials ANd Methods}

\subsection{Study Site}

Ngaoundere is the head quarter of the Adamawa region. It falls within the following geographical limits, latitude $6^{\circ}$ and $8^{\circ}$ north of the equator and longitude $11^{\circ}$ and $15^{\circ}$ east. Ngaoundere falls in the tsetse free belt of Cameroon. It has a Soudano-Guinean climate with two seasons (rainy and dry). The vegetation of Ngaoundere ranges from savanna, gallery forest and secondary forest. Ngaoundere is host for the main cattle market of the region and is in Mbidjoro that constituted our study site. Mbidjoro is $15 \mathrm{~km}$ from the town of Ngaoundere along the Tibati motorable high way. The study site constituted of a mixed cattle herd with three breeds (Goudali, Akou, Charolais and Holstein) and their cross breeds (metis) (appendix 9). The cattle overnight pen was located 50 to $100 \mathrm{~m}$ away from four poultry farm buildings. The poultry blocks were not fly proof. Eight herds of cattle were found in the sampling area. The cattle density of the study site was 241 cattle heads $/ 7 \mathrm{Km}^{2}$.

\subsection{Design of the Vavoua Trap}

The different textile parts of the trap must be cut so as to use the maximum amount of fabric from the piece. Black screens $(76 \times 28 \mathrm{~cm}$ ): in a $100 \mathrm{~m}$ by $1.80 \mathrm{~m}$ wide piece (Figure 1B). The blue screens (trapezium like, $76 \times 48 \times 27 \mathrm{~cm}$ ) cut head to tail (Figure 1B): in a $100 \mathrm{~m}$ piece by $1.50 \mathrm{~m}$ wide; the $15 \mathrm{~cm}$ drop, after longitudinal stitching, still provides a considerable number of screens (Figure 1G). The cone is mounted in three parts, each with an apex angle of 56 degrees and a radius of $78 \mathrm{~cm}$ and slant height of $85 \mathrm{~cm}$ (Figure 1F). Assembly of the three black screens: two of the screens are superimposed and then sewn longitudinally $13 \mathrm{~cm}$ from the edge; an identical seam is made between the 1st screen and the 3rd arranged along the opposite edge; finally the 2nd and 3rd screens are sewn together in the same way (Figure 1D). This creates a $2 \mathrm{~cm}$ groove for the passage of the fixing material and the trap (Figure 1D). Between the free edges and two black screens, insert a $0.5 \mathrm{~cm}$ blue screen, aligning the upper edges, then sew longitudinally (Figure 1C). The internal part of the trap thus produced is then sewn with the three sectors of the cone: the screens are then placed at 120 degrees (Figure 1C).

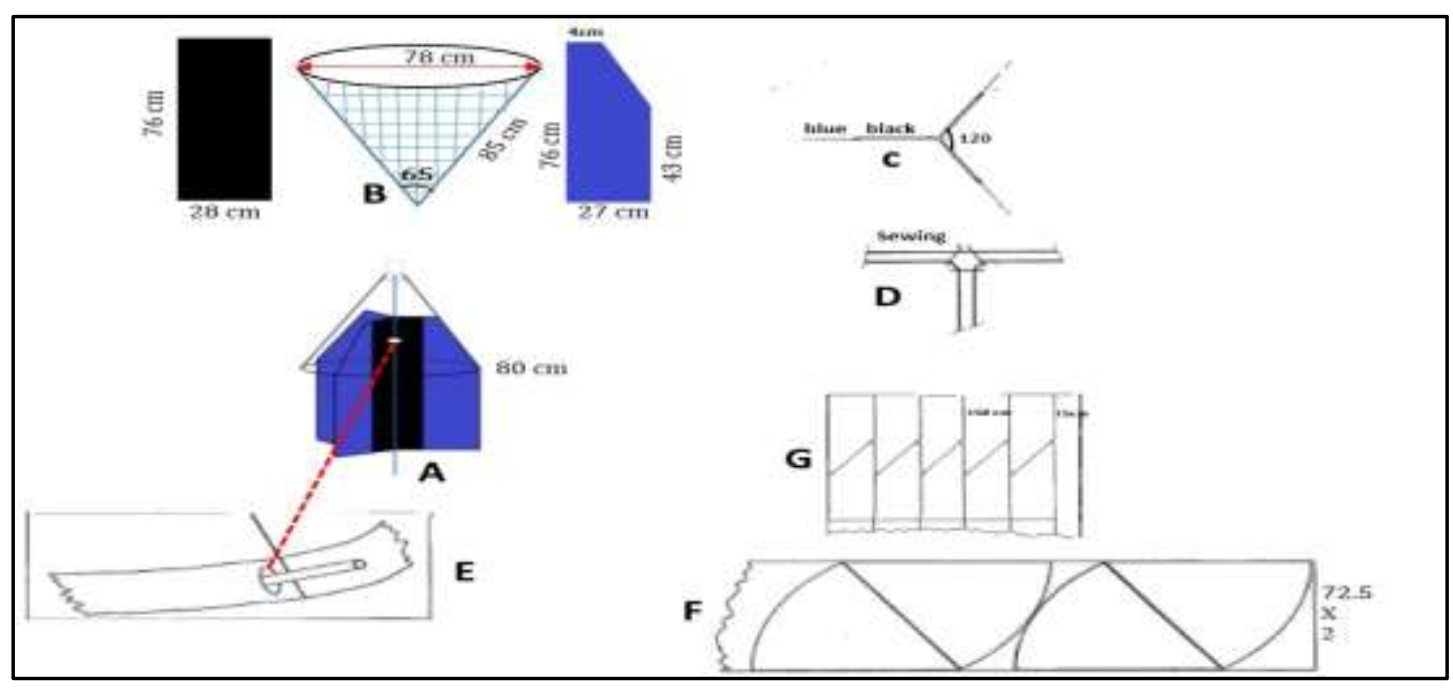

Figure1. Design of the Vavoua trap (source: Laveissière and Grébaut, 1990). (A): Vavoua trap (articulated system); $(\boldsymbol{B}):$ the different fabric parts, $(\boldsymbol{C})$ : stitching of the three black parts; $(\boldsymbol{D})$ : stitching of the blue and black parts; $(\boldsymbol{E})$ detail of the throat (see text); $(\boldsymbol{F})$ cutting of the three parts of the cone; $(\boldsymbol{G})$ : cutting of the blue fabrics. 
For capture, the end of the cone is truncated to allow the lacing support system to pass. For the cone, it is protected from the metallic axis by a carded cotton pad, a piece of string around the top holds the whole. The rigidity of the cone can be ensured by a circlular galvanized wire of $80-81 \mathrm{~cm}$ in diameter (Figure 1A). When setting up, the bottom of the trap must be between 30 and $40 \mathrm{~cm}$ from the ground. The length of the iron rod ( $8 \mathrm{~mm}$ concrete iron) will essentially depend on the nature of the site: it is advisable to use $1.50 \mathrm{~m}$ iron rod as support.

\subsection{Design of the Modified Vavoua Trap (MVT)}

The MVT (Sevidzem et al., 2019b) is a simple blue/black polyester trap with a trapezium-like blue/black core in the mosquito net section. The section of the trap protruding to the bottom of the mosquito net is in the form of a blue-black flat screen. The size of the MVT is $132 \mathrm{~cm} \mathrm{x} 84 \mathrm{~cm}$ (Figure 2A-E). This trap has the same trapping mechanism as the Vavoua and Nzi. Its ability to capture dipterous insects relies only on the visual cue offered by the blue and black colors of its cloth. Concerning the specific dimensions of this trap, the trapezium-like blue-black pieces each has the following dimensions: base length of $42 \mathrm{~cm}$, length of the top is $10 \mathrm{~cm}$, vertical height is $36 \mathrm{~cm}$, and the slanting height is $52 \mathrm{~cm}$ (Figure 2B). The rectangular blue and black pieces each has a dimension of $40 \mathrm{~cm}$ height and $42 \mathrm{~cm}$ width (Figure 2C). The mosquito net sewn to cover the collection cage has a dimension of $10 \mathrm{~cm}$ height and $5 \mathrm{~cm}$ width (Figure 2D). The mosquito net section designed in the form of a cone has a bottom diameter of $84 \mathrm{~cm}$, a top diameter of $4 \mathrm{~cm}$, and a height of $82 \mathrm{~cm}$ (Figure $2 \mathrm{E})$. The entire trap is held by a vertical iron rod of $1.5 \mathrm{~m}$ in length. The distance from the ground to the trap must be maintained at $20 \mathrm{~cm}$ (Figure 2A).

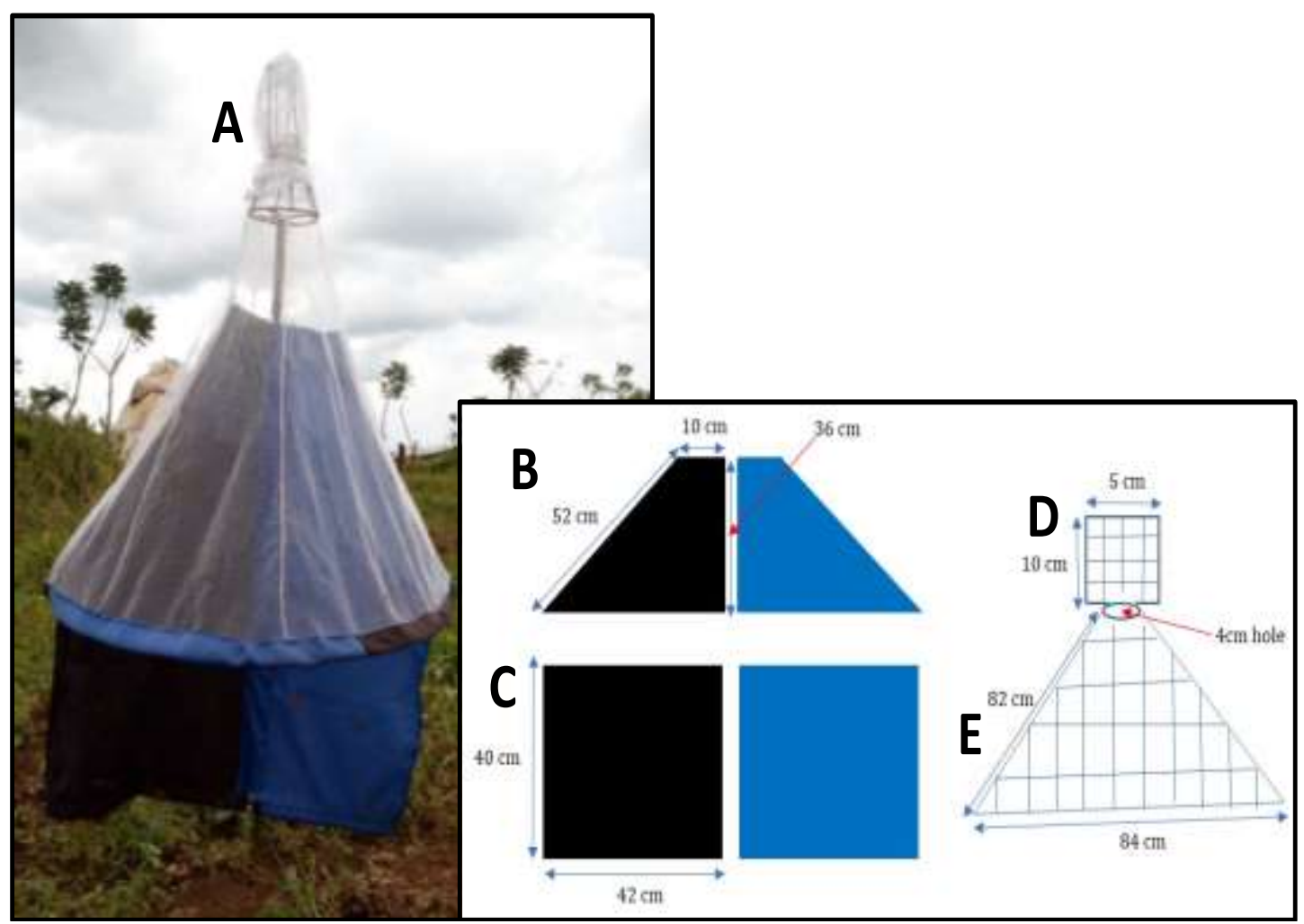

Figure 2A-C. Modified Vavoua trap (source: original conception). (A): Modified Vavoua Trap, (B):trapeziumlike blue and black polyester clothes, $(\boldsymbol{C})$ :rectangular blue and black polyester clothes, $(\boldsymbol{D})$ : Collection cages, and $(\boldsymbol{E})$ :Cone-like mosquito net section.

\subsection{The Nzi Trap}

The Nzi is a blue-black trap like the MVT but is larger in size (Figure 3). This trap is originally designed by Mihok at ICIPE. This trap consist of a $1 \mathrm{~m}$ x $1 \mathrm{~m}$ mosquitoe net. Blue and black cloth pieces of $0.5 \mathrm{~m} \times 1 \mathrm{~m}$ in dimension that are sewn to form the wings of this trap (Figure 3).Thehorizontal net shelfforms the roof of this trap and holds the collecting cage. The trap is supported by four sticks or iron rods with atleast six tension points that makes the trap very cumbersome. 


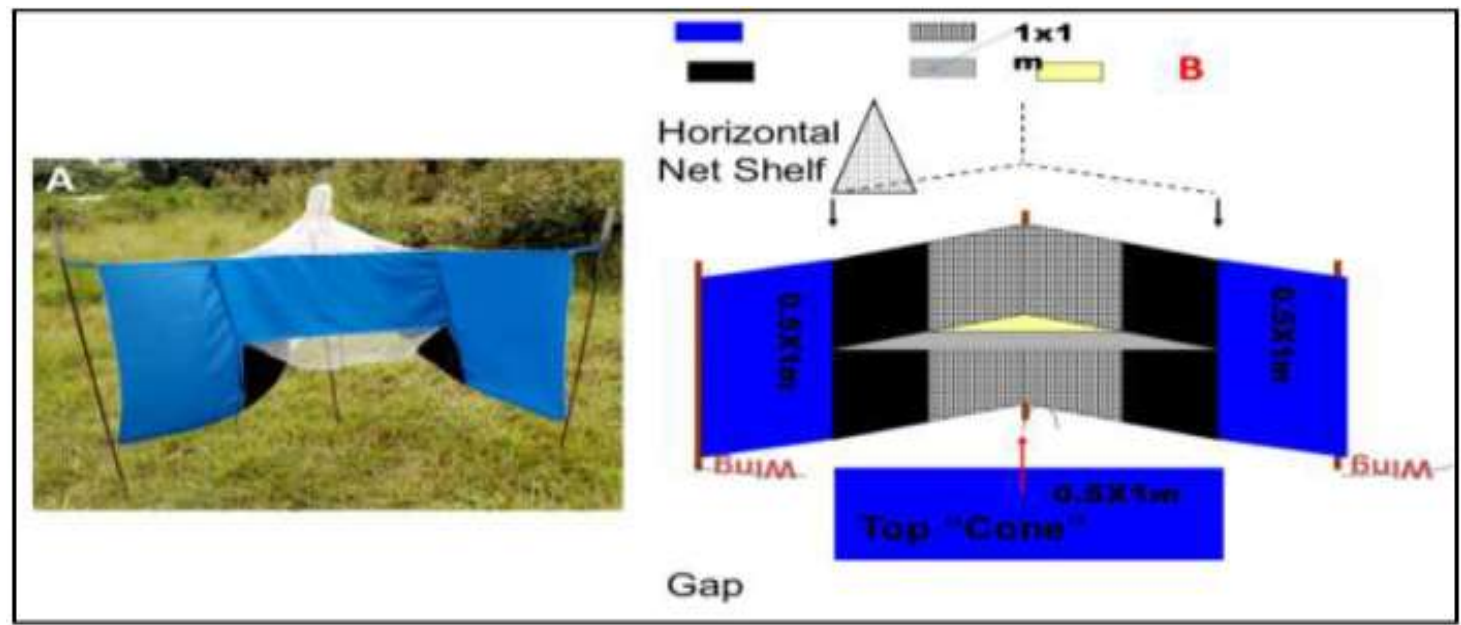

Figure3. Presentation of the Nzi trap (source: Mihok S.).(A) The Nzi trap (Source: original), (B) The schematic presentation of the Nzi trap.

\subsection{Study Design}

Unbaited Nzi and Modified vavoua (MVT) traps were pitched, one inside the cattle overnight stable and the other outside the grazing field (Figure 4). The two trap types were $500 \mathrm{~m}$ from each other. A $2 \times 2$ Latin square with rotation experimental design was used. The cages of the traps were emptied every 24hours. Flies were collected into well labelled plastic bags for identification using a dissecting microscope. The trapping effort was 2 traps $x 8$ days in the rainy season (August to September) $=16$ traps days.
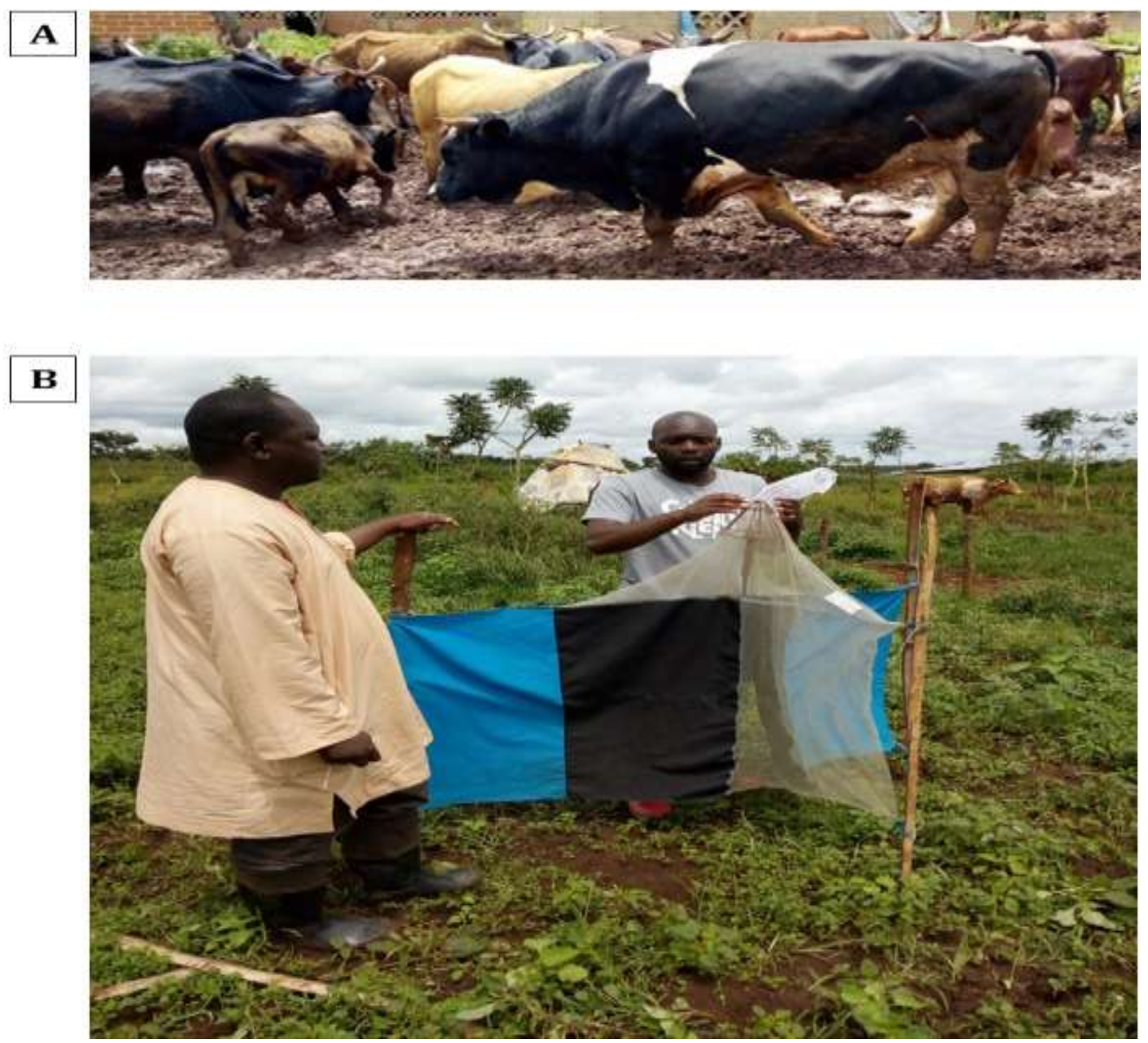

Figure4. The position of traps. $(\boldsymbol{A})$ : inside the cattle pen, $(\boldsymbol{B})$ : outside the cattle pen. 


\subsection{Fly Identification}

Stomoxys spp. were identified using the key of Zumpt (1973). Tabanids identification was realised using the morphological key of Oldroyd (1957). The identification of the genus Musca was made using the key of Gregor et al., (2002).

\subsection{Data Analysis}

The abundance was defined by the Trap Apparent Density (ADT) known as the number of Stomoxys caught per trap and day as follows:

$\mathrm{ADT}=\frac{\text { Number of flies caught }}{\text { Number of traps } \times \text { Number of trapping days }}$

The specificity was calculated using the following formula :

Specificity $(\%)=\frac{\text { Total number of the individuals of a particular species }}{\text { Total number of the individuals of all species caught }} \times 100$

The JASP statistical software of version 0.8.5.1 was used for the statistical analyses. The mean catches of the trap types and their positions were compared using the Student t-test. The statistical test was kept at the $\mathrm{P}<0.05$ significant level.

\section{RESUlts}

The entomological prospection resulted in 2105 flies with the following flies identified with their apparent abundances in order of magnitude: 1417 S. n. niger (89 S.n/t/d), 562 Musca spp. (25 m/t/d), 124 S. calcitrans $(8 \mathrm{~S} . c / t / d)$ and 2 C. distinctipennis $(0.1 \mathrm{Cd} / \mathrm{t} / \mathrm{d})$.

\subsection{Catches with respect to Trap Type}

The MVT caught muscids (Musca spp. and Stomoxys spp.) but failed to catch tabanids. The Nzi trap caught all flies including Musca spp., Stomoxys spp., and Chrysops (Figure 5). The number of muscids caught by the MVT was higher for each species than with the Nzi.

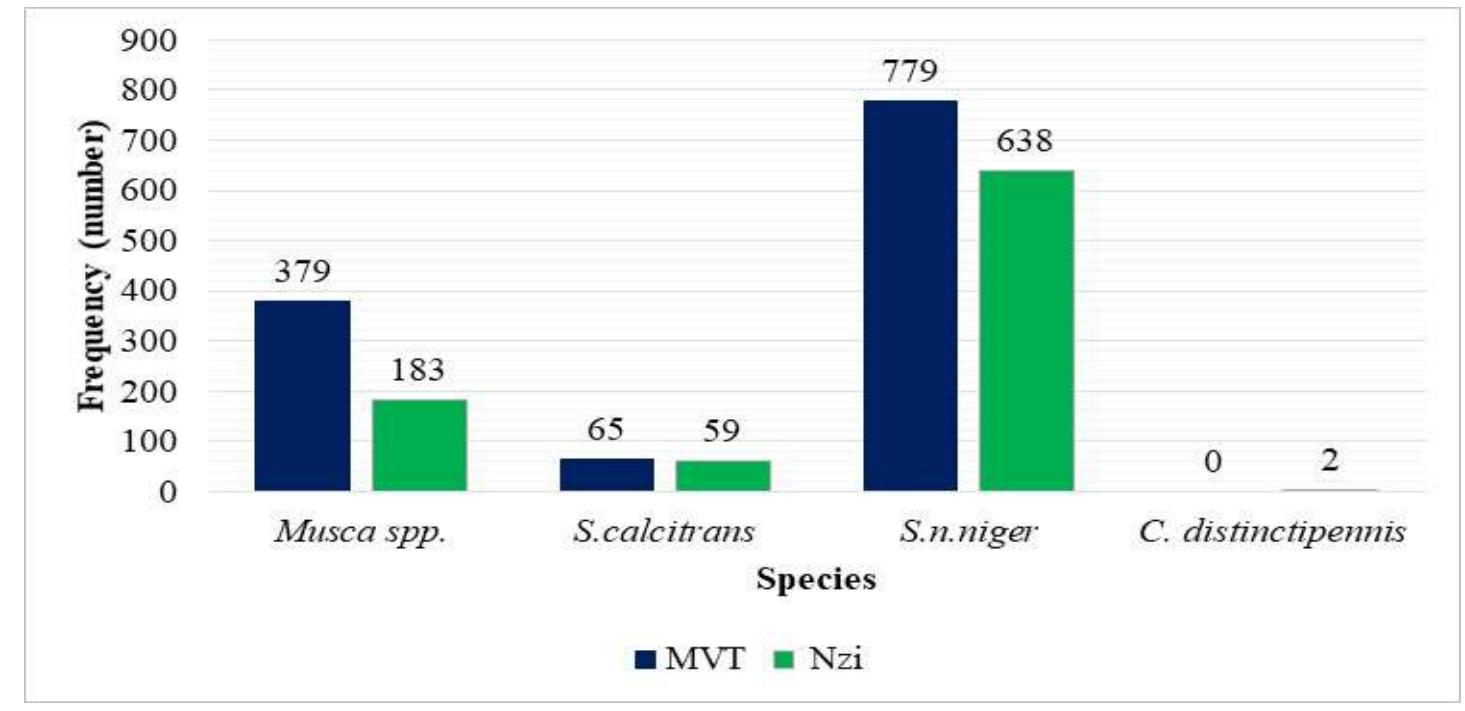

Figure5. Fly species caught with respect to trap type.

The specificity of the MVT was higher for S. niger niger (54.97\%) and S. calcitrans $(52.42 \%)$ as compared to Nzi, but the Nzi trap recorded $100 \%$ specificity for $C$. distinctipennis and zero with the MVT (Figure 6). 


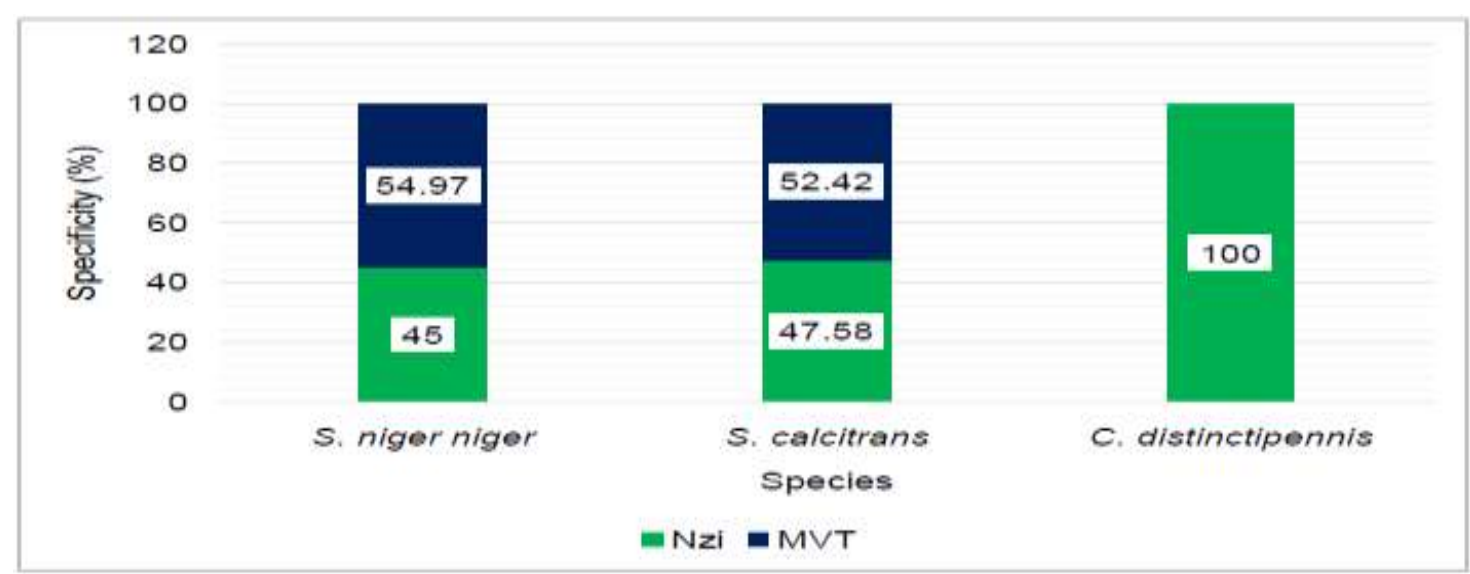

Figure6. Specificity of trap types

\subsection{Fly Catches with Position of Traps}

The Musca spp. count was higher outside the cattle pen than inside (Figure 7). Stomoxys calcitrans had the same catches when traps were pitched either inside or outside the cattle pen (Figure 7). Stomoxys niger niger catches were higher outside than inside the cattle pen (Figure 7).

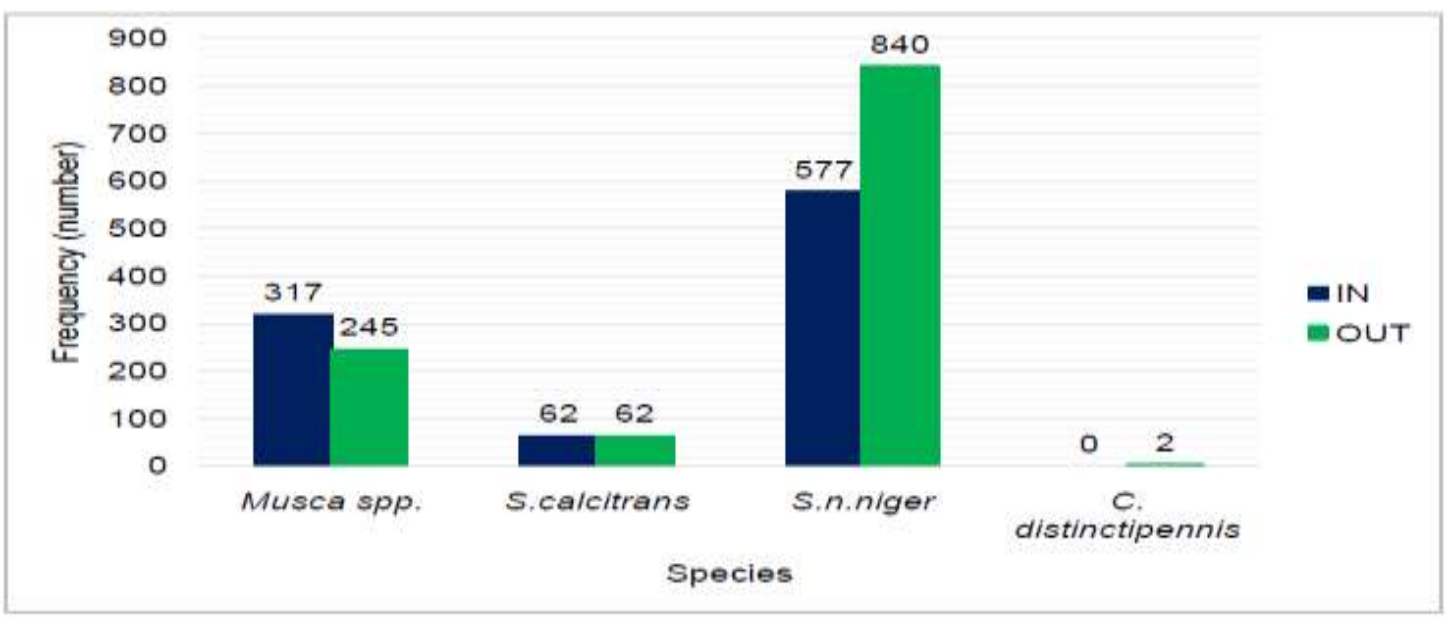

Figure7. Fly catches with position of traps.

\subsection{Efficiency of Trap-types Based on Mean Catches}

The mean catches with trap types revealed a higher mean catch with the MVT $(50.96 \pm 57.16)$ as compared to the Nzi $(27.43 \pm 27.79)$ even though there was no statistically significant difference $(\mathrm{t}=$ $0.9, \mathrm{df}=46.0, \mathrm{P}=0.37$ ) with catches of the two trap types. Regarding the position of the trap types, there was a higher mean catch outside $(47.79 \pm 55.27)$ the cattle pen than inside $(39.83 \pm 55.40)$ with no statistically significant difference $(\mathrm{t}=0.5, \mathrm{df}=46.0, \mathrm{P}=0.62)$ (Table 1$)$.

Table1. Mean fly catches based on trap models and position

\begin{tabular}{|c|c|c|}
\hline Parameters & Number & Mean \pm Standard deviation \\
\hline Trap models & $\mathrm{t}=0.9, \mathrm{df}=46.0, \mathrm{P}=0.37$ & $27.43 \pm 27.79$ \\
\hline Nzi & 882 & $50.96 \pm 57.16$ \\
\hline MVT & 1223 & $39.83 \pm 55.40$ \\
\hline Position of trap models & $\mathrm{t}=0.5, \mathrm{df}=46.0, \mathrm{P}=0.62$ & $47.79 \pm 55.27$ \\
\hline Inside & 956 & \\
\hline Outside & 1149 & \\
\hline
\end{tabular}

\section{DISCUSSION}

The occurrence of tabanids and Stomoxyini in the rangeland of Ngaoundere has already been reported (Lendzele et al., 2019). In our study, high numbers of stable flies were caught outside the cattle pen as compared to the inside. The high catches outside could be due to the proximity of the traps to the 
breeding sites of the stable flies (Mavoungou et al., 2017; Murchie et al., 2018) because stomoxyines developmental substrates consist of faecally-soiled surfaces and decomposing vegetation as well as beddings from poultry (Baleba et al., 2020) and such potential breeding material were found outside the cattle overnight pen where cattle graze as compared to the muddy nature of the inside of the cattle overnight stable. In addition, the poultry blocks found around the grazing field located outside the pen did not have fly proofs and were probable source of stable flies. Hogsette and Ose (2017) reported high catches inside the periphery of the zoological parks with no statistically significant difference with catches inside and outside. According to Hogsette et al., (1989) best catches of stable flies are made near animals, but Murchie et al., (2018) realised that stable flies were collected with sticky traps placed at the periphery of a cattle pen. The blue/black colour of the traps used in this trial simply mimic the natural forest edges where stable flies rest and digest their blood meal as well as the two colours reflect light in the U.V range (Mihok et al., 2006; Sevidzem et al., 2019c).

Despite the use of insecticide in fly control in most areas in Africa, the obvious shortcoming remains the development of insecticide resistance (Olafson et al., 2019) and its toxic effect on non-target population such as honey bees. An alternative of insecticide usage for fly control is the use of parasitoids (Baleba et al., 2020) and traps that are environmentally friendly (Sevidzem and Mavoungou et al., 2019). Some of the most common traps used for the control of important pasture flies like tsetse, tabanids and Stomoxyini, include Nzi, Vavoua and Biconical and the Vavoua that has been reported to be highly specific to stable flies (Sevidzem and Mavoungou, 2019; Hiol et al., 2019; Sevidzem et al., 2019d). However, the Vavoua (10 to 12 Euros) is expensive, difficult to reproduce and not easily available to local farmers and fly control authorities. The modified Vavoua trap (MVT) is a descendant of the Vavoua and is cheaper (7 Euros), simple, easily reproducible, highly specific and available to local farmers of Adamawa through a farmer association (Production Laitiere et Embouche Bovine, Ngaoundere Cameroon). The Nzi trap is most expensive (14 to 16 Euros) of all the tsetse traps and difficult to transport in the field, but is very expensive. The results of this study indicates that the efficicacy and specificity of the MVT to Stomoxys calcitrans and Stomoxys niger niger was similar to that of the Nzi which is a standard trap. The MVT was unable to catch tabanids that were caught by the Nzi even though with scanty catch. We cannot say that the MVT cannot catch tabanids because the trial was conducted in August and September, characterised by heavy rains and weak abundance of tabanids in Ngaoundere (Sieumeni et al., unpublished data). However, we need to conduct a longitudinal prospection with the MVT, original Vavoua and Nzi in different bioclimatic regions in order to validate this new tool.

\section{CONCLUSION}

We designed a trap known as the modified Vavoua trap (MVT) which is a descendant of the Vavoua trap, it is cheaper and easily reproducible than the Vavoua and Nzi and is available to farmers of the Adamawa region. The MVT recorded similar results in terms of specificity and efficiency as Nzi. The MVT and Nzi traps caught more biting muscids outside the pen as compared to inside. This trap is important because it can reduce the population of stable flies as well as act as a re-infestation barrier for biting fly free rangelands.

\section{ACKNOWLEDGEMENTS}

The study was successful thanks to the field assistance of Mr Aboubakary (Veterinary technician) and Miss Kong Anita (DVM student). The study was successful thanks to the BWS-REK grant received by the first author. Authors acknowledge the technical support of the Laboratory of Vector Ecology (LEV) of the Institute of Research in Tropical Ecology (IRET) in Gabon.

\section{REFERENCES}

[1] Bastien F. 2008. Effet larvicide des huiles essentielles sur Stomoxys calcitrans a la Réunion. Thèse pour Obtention le grade de Docteur Vétérinaire de l'Université Paul-Sabatier de Toulouse, p. 78.

[2] Baleba SBS, Torto B, Masiga D, Getahun MN, Weldon CW, 2020. Stable flies, Stomoxys calcitrans L. (Diptera : Muscidae), Improve Offspring Fitness by Avoiding Oviposition Substrate with Competitors or Parasites. Frontiers in Ecology and Evolution, 8, 5.

[3] Hiol V, Sieumeni AD, Mamoudou A, Sevidzem SL, Njan-Nloga AM, Nukenine EN. Spatio-Temporal Dynamics of Glossinidae, Tabanidae and Stomoxyidae around the Douala-Edea Wildlife Reserve in Cameroon. 2019. American Journal of Entomology, 3, 36-42. 
[4] Hogsette JA and Ose GA. 2017. Improved capture of stable flies (Diptera: Muscidae) by placement of knight stick sticky fly traps protected by electric fence inside animal exhibit yards at the Smithsonian's National Zoological Park. Zoo Biology, 36, 382-386.

[5] Laveissière C, Grébaut P. 1990. Recherche sur les pièges à glossines (Diptera : Glossinidae). Mise au point d'un modèle économique : le piège «Vavoua». Tropical Medicine and Parasitology, 41, 185-192.

[6] Lendzele SS, Eisenbarth A, Zinga-Koumba RC, Mavoungou JF, Renz A. 2019. Aspects of the bionomics of hematophagous symbovine dipterans in a hyper-infested rangeland of Ngaoundere (AdamawaCameroon). Journal of Asia-Pacific Entomology, 22, 1019-1030.

[7] Mamoudou A, Sevidzem SL, Feussom JM, Abdoulay M. 2017. Deltamethrin Coated Screen against Tsetse and Trypanosomosis. Walailak Journal of Science and Technology, 14, 893-909.

[8] Mavoungou JF, Nguema RM, Acapovi GL, Koumba RZ, Mounioko F, Sevidzem SL, Bakakas IK, Gilles J, Duvallet G, M'Batchi B, Picard N. 2017. Breeding Sites of Stomoxys spp. (Diptera: Muscidae), a Preliminary Study in the Makokou Region (North-East-Gabon). Vector Biology Journal, 2, 1.

[9] Mihok S, Carlson DA, Krafsur ES, Foil LD. 2006. Performance of the Nzi and other traps for biting flies in North America. Bulletin of Entomology Research, 96, 387- 397.

[10] Murchie AK., Carol EH, Alan WG, Clawson S. 2018. Black Border Increases Stomoxys calcitrans Catch on White Sticky Traps. Insects, 9, 13.

[11] Olafson PU, Kaufman PE, Duvallet G, Solorzano JA, Taylor DB, Fryxell RT. 2019. Frequency of kdr and kdr-his Alleles in Stable Fly (Diptera:Muscidae) Populations From the United States, Costa Rica, France, and Thailand. Journal of Medical Entomology, 1-5.

[12] Oldroyd HMA. 1957. The horse flies (Diptera : Tabanidae) of the Ethiopian region. Subfamilies, Chrysopinae, Scepsidinae and Pangonunae and a revised classification. Bristish Museum (Natural History), London, 3, 489.

[13] Sevidzem SL and Mavoungou JF. 2019. Relative Efficacy of Tsetse Traps and Live Cattle in Estimating the Real Abundance of Blood-Sucking Insects. Journal of Applied Sciences, 19, 690-700.

[14] Sevidzem SL, Mavoungou JF, Mintsa NR. 2019a. Veterinary pharmaceuticals sold in cattle markets for the management of footand-mouth disease and flies in Vina division (Adamawa-Cameroon). Dairy Veterinary Science Journal, 10, 2.

[15] Sevidzem SL, Affiri OJM, Zinga-Koumba CR, Mounioko F, Koumba AA, Nguema RM, Acapovi-Yao GL, M'batchi B, Mavoungou JF. 2019b. Abundance and Diurnal Activity Rhythm of Stomoxys spp. in a Wildlife-human Interface in Makokou (North East-Gabon). Asian Journal of Research in Zoology, 2, 1-10.

[16] Sevidzem SL, Tchawe R, Zinga-Koumba R, Mamoudou A, Ndjonka D, Mavoungou JF. 2019c. Insecticide coated screen models reduce insect-vector population in a pasture area in Ngaoundere, Cameroon. Trends Applied Science and Research, 14, 80-89.

[17] Sevidzem SL, Mavoungou JF, Zinga-Koumba CR, Koumba AA, Duvallet G. 2019d. Factors Influencing Seasonal and Daily Dynamics of the Genus Stomoxys Geoffroy, 1762 (Diptera: Muscidae), in the Adamawa Plateau, Cameroon. International Journal of Zoology, 9.

[18] Solórzano JA, Gilles J, Bravo O, Vargas C, Yannery GB, Bingham GV, Taylor DB. 2015. Biology and Trapping of Stable Flies (Diptera: Muscidae) Developing in Pineapple Residues (Ananas comosus) in Costa Rica. Journal of Insect Science, 15, 145.

[19] Tainchum K, Shukri S, Duvallet G, Etienne L, Jacquiet P. 2018. Phenotypic susceptibility to Pyrethroids and Organophosphates of wild Stomoxys calcitrans (Diptera: Muscidae) populations in South western France. Parasitology Research, 117, 4027-4032.

[20] Williams DF. 1973. Sticky traps for sampling populations of Stomoxys calcitrans. Journal of Economic Entomology, 66, 1279-1280.

[21] Zumpt F. 1973. The Stomoxyine biting flies of the world. Diptera: Muscidae. Taxonomy, biology, economic importance and control measures. Stuttgart: Gustav Fischer Verlag, p. 175.

Citation: Sevidzem Silas Lendzele et al., "Efficacy of Modified Vavoua and Nzi Traps in the Capture of Stable Flies: A Preliminary Field Trial in Cameroon", International Journal of Research Studies in Biosciences, 8(6), pp. 10-17. DOI: https:// doi.org/10.20431/2349-0365.0806004

Copyright: () 2020 Authors, This is an open-access article distributed under the terms of the Creative Commons Attribution License, which permits unrestricted use, distribution, and reproduction in any medium, provided the original author and source are credited. 